\title{
GM Crops: Dream to Bring Science to Society
}

\author{
Asis Datta
}

Received: 6 January 2012 / Accepted: 13 January 2012/Published online: 1 March 2012

(C) NAAS (National Academy of Agricultural Sciences) 2012

\begin{abstract}
Attaining the food and nutritional security for the present as well as future generations is an uphill task. The world faces mounting challenges from increasing population growth, climate changes, and diminishing natural resources. The world must keep on producing enough nutritious and safe food under these adverse conditions. The present scenario points toward the adaptation of crop improvement technologies which are faster and environment-friendly. Genetically modified (GM) crops developed through modern plant biotechnology tools have enormous potential to contribute toward sustainable agricultural development. In this context, our study using several novel genes for crop improvement will be discussed. These GM crops can help us in alleviating many current and future problems in agriculture.
\end{abstract}

Keywords GM crops - Anti-nutritional factors - Tolerance to biotic stresses - Nutritive food crops ·

Enhancement of fruit shelf life

\section{Introduction}

Humans require adequate amounts of nutritionally balanced foods throughout the life for proper growth, development and combat disorders, and diseases. Food and nutritional insecurity poses serious concerns for human health worldwide, especially in developing countries due to continuous rise in population. Therefore, promoting the nutritional value of staple crops is a major consideration for global food and nutritional security. Previous efforts mostly comprising conventional breeding practices can no longer maintain pace with the increasing demands for quality food because of crossability barriers and uncertainty over genomic changes. Therefore, new technologies must be adopted for crop improvement. In the recent past, transgenic technology has proved to be greatly useful in serving the purpose of crop improvement with respect to increased nutritional quality and productivity.

\footnotetext{
A. Datta $(\bowtie)$

National Institute of Plant Genome Research, JNU Campus, Aruna Asaf Ali Marg, New Delhi 110067, India

e-mail: asis_datta@rediffmail.com; asis_datta@nipgr.res.in
}

Modern biotechnologists or genetic engineers are becoming the new partners of agricultural scientists. They see new ways of tackling old problems, through application of plant molecular biology. The progress will be driven by the discovery and characterization of genes and gene products of known function in model and economically important plants and the ability to design and insert new genes into an ever-widening range of plant species.

Here, I present some of the investigations from our laboratory that deal with genetically modified (GM) crops serving improved nutritional quality, enhanced resistance against fungal diseases, and improvement of shelf life of fruits and vegetables.

\section{Reducing Anti-Nutritional Factors and Enhancing Tolerance to Biotic Stress}

Fruits and vegetables which are important source of vitamins and minerals to human diet also contain oxalic acid as an antinutritional factor. Consumption of high oxalic acid containing fruits and vegetables is detrimental to human health as oxalate chelates calcium. This leads to precipitation of calcium 
oxalate in the kidney which causes hyperoxaluria and destruction of renal tissues [5, 8]. In addition, synthesis and secretion of oxalic acid have been linked with the pathogenesis of several phytopathogenic fungi, such as Sclerotinia scleriotorum,

S. rolfsii, and S. ceptivorum. S. scleriotorum has a very wide host range and causes significant yield losses in several economically important crops like tomato, oil seed rape, bean, and sunflower. Oxalic acid is known to accumulate at the site of infection of some fungal phyto-pathogens. Its concentration increases during the early pathogenesis and pathogen colonization. Accumulation of high level of oxalic acid in leaves results in wilting and finally leaf death. Oxalic acid also serves as substrate for the synthesis of a neurotoxin, $\beta$ - $N$-oxalyl-L$\alpha, \beta$-diaminopropionic acid (ODAP) present in Lathyrus sativus [17]. Consumption of $L$. sativus leads to neuro-lathyrism which is characterized by spasticity of leg muscles, lower limb paralysis, convulsions, and death [11]. Thus, L. sativus cannot be grown and consumed as food, although it is a high proteincontaining hardy legume which can withstand draught and water-logging conditions [15]. The above mentioned facts highlight oxalic acid as an important stress factor.

The functional expression of oxalic acid degrading enzyme in crops is an important crop improvement strategy by reducing the anti-nutritional factor as well as by conferring tolerance to fungal pathogens. Our laboratory isolated, for the first time, an enzyme known as oxalate decarboxylase (OXDC) from Flammulina velutipes [13]. This enzyme provides several advantages over other oxalate-degrading enzymes, such as oxalate oxidase. Primarily, it is very specific to oxalate which is catabolized to non-toxic formic acid and $\mathrm{CO}_{2}$ in a single-step reaction without any cofactor. This enzyme is also active at low $\mathrm{pH}$ which is important, as most of the oxalate is localized in vacuoles of plant cell. Further, we cloned for the first time the gene OXDC from C. velutipes [13]. Expression of this gene in tomato (Fig. 1) and tobacco resulted in transgenic lines with improved resistance to infection by S. sclerotiorum [10]. Development of fungal resistance in transgenic plants was found to be correlated with the induction of several pathogenesis-related genes. Our study represented a novel approach to develop transgenic plants resistant to fungal pathogens and free of anti-nutritional compound.

\section{Increased Nutritive Value of Food Crops}

Protein deficiency is the most crucial factor that affects physical growth and development, and this factor increases morbidity and mortality especially in developing countries. A large proportion of world's population is suffering from protein malnutrition. To maintain optimal health, nutritionally balanced foods must be included in the diet. Humans largely depend on plant-based foods for the daily nutritional requirements. Therefore, staple crops are the targets for the nutritional enhancement through genetic manipulation. Owing to the significance of well-balanced proteins in diet mostly based on plants, enrichment of protein levels and the concentration of essential amino acids in staple crops are of prime consideration in a crop improvement program. In this context, major efforts have been to improve the amino acid composition of seed proteins. For years, conventional breeding methods have been practiced to develop protein-rich crops having balanced amino acids composition. Genetic engineering complements conventional approaches for improving the nutritional quality of crops. Several attempts have been made to increase the free essential amino acids in crops through mutant selection and manipulating genes involved in amino acid biosynthesis [12]. However, these efforts have met with limited success [6]. One promising approach is the introduction of genes encoding high-value proteins into food crops.

Amaranth seeds are rich in proteins (17-19\% of seed dry weight) with balanced amino acid composition. The protein of this pseudo-cereal is rich in many essential amino acids, e.g., lysine, tryptophan, and sulfur-containing amino acids. Therefore, we used amaranth to search for the gene that encodes high nutritional value protein [16]. Our laboratory, for the first time, identified and cloned a gene $A m A l$ from Amaranth that encodes a $35-\mathrm{kDa}$ protein, rich in essential amino acids. Amino acid composition of AmA1 was found to be even better than that recommended by the World Health Organization for a protein to be optimal for human nutrition [4]. More importantly, owing to its non-allergenic nature and origin from an edible crop, the transgenic crops expressing AmA1 would have better consumer acceptability.

We selected potato for nutritional improvement using AmAl gene owing to its importance as non-cereal food crop. Potato ranks fourth in terms of total global food production. However, this starchy crop is a poor source of many essential amino acids, such as lysine, tyrosine, and the sulfur-containing amino acids methionine and cysteine [9]. This limits the nutritive value of potato. In our laboratory, tuber-specific expression of $A m A I$ in potato resulted in a significant increase in the concentration of most essential amino acids [3]. The total protein content in transgenic tubers also increased in comparison with control plants. For the first time, our research study demonstrated the utility of $A m A l$ gene for the genetic improvement of food crops with nutritionally balanced protein. As geographical distribution of crops is influenced by agroclimatic conditions, we translated this novel crop improvement approach into several commercially important potato varieties adapted to different agro-climatic regions. Seven 
Fig. 1 GM tomato (oxalatefree) tolerant to Sclerotinia scleriotorum

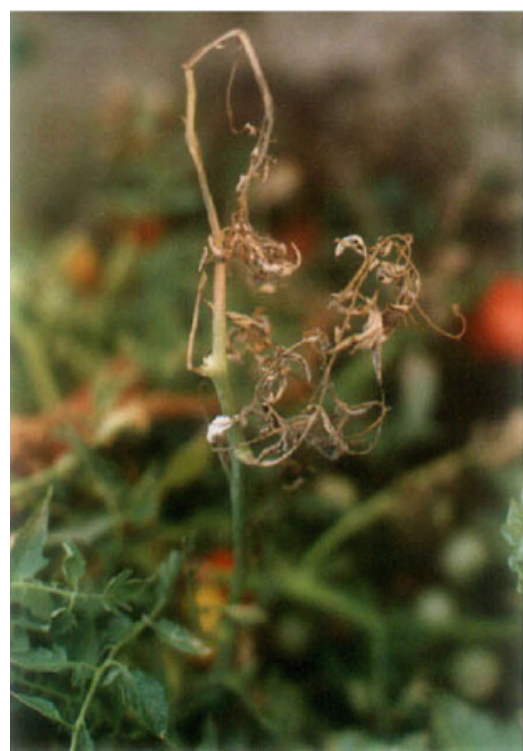

Wild Type

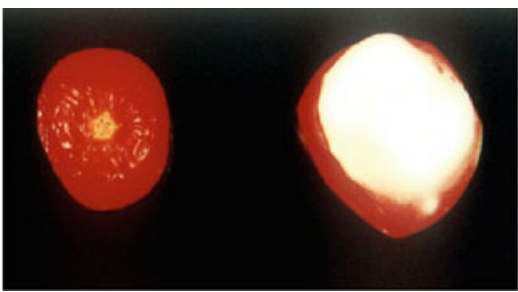

Infected

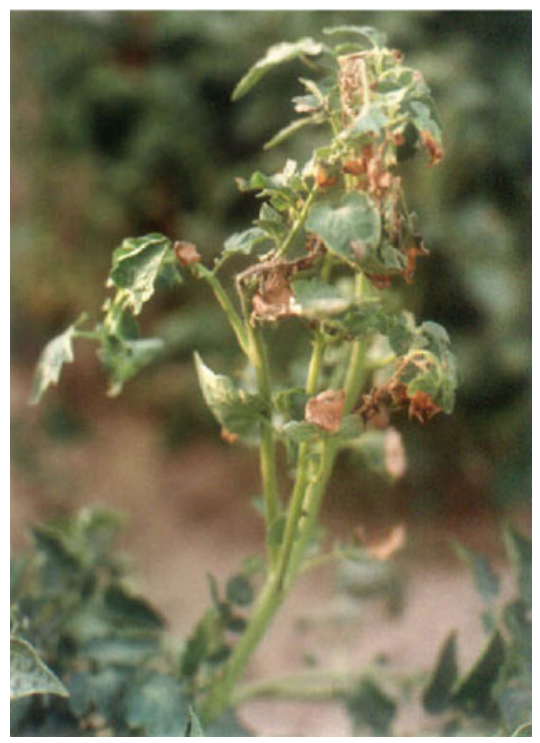

Transgenic

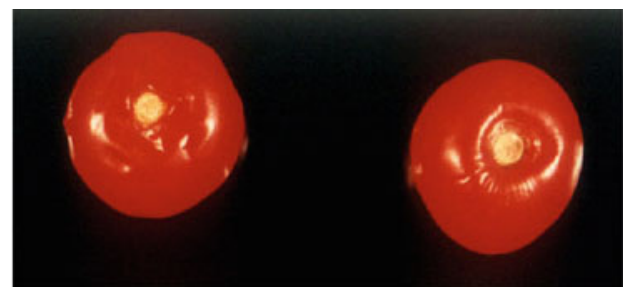

Uninfected

Infected

potato varieties were transformed with $A m A l$ with tuberspecific expression [4]. The results obtained from field trials (Fig. 2) in an advanced generation of the transgenic lines revealed up to $60 \%$ increase in total protein content in transgenic tubers. Besides, the concentrations of several essential amino acids in transgenic tubers were found to be increased significantly. Moreover, the transgenic potato plants expressing AmAl showed enhanced rate of photosynthesis along with increase in total biomass and a moderate increase in tuber yield [3]. The field performance and biosafety assessment of AmA1 potatoes suggest that transgenic protein-rich potatoes are safe for human consumption and suitable for commercial cultivation.

\section{Enhancement of Fruit Shelf Life}

Enhancement of fruit shelf life is of strategic importance as post-harvest losses of fruits and vegetables in many countries account for almost $50 \%$ of the produce. India is the world's second largest producer of fruits and vegetables. In India, post-harvest losses of perishable fruits and vegetables may be as high as $35-40 \%$. The main factor that determines the shelf life of fruits and vegetables crops is the rate of softening during ripening. This aggravates the

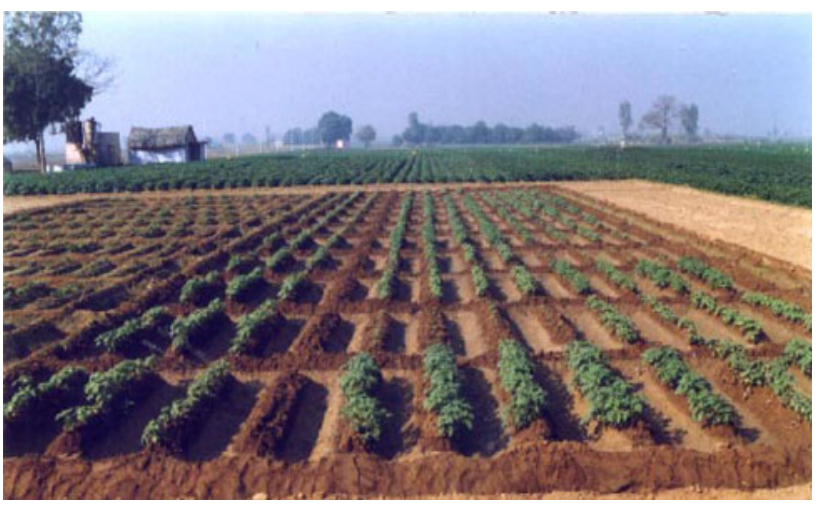

Fig. 2 Field trial of GM potatoes, with enhanced nutritive value by tuber-specific expression of a seed protein AmA1 (Amaranth albumin 1), conducted in collaboration with the Central Potato Research Institute of the Indian Council of Agricultural Research

physical damage during handling and transportation, and increases the susceptibility to post-harvest pathogens $[1,2$, 18]. All these lead to decrease in overall shelf life of fruits and vegetables. Therefore, for the enhancement of fruit shelf life and control of post-harvest losses, fruit softening process is the main target for the genetic manipulation. Some approaches to control fruit softening during ripening are based on slowing down the rate of biosynthesis of 
A

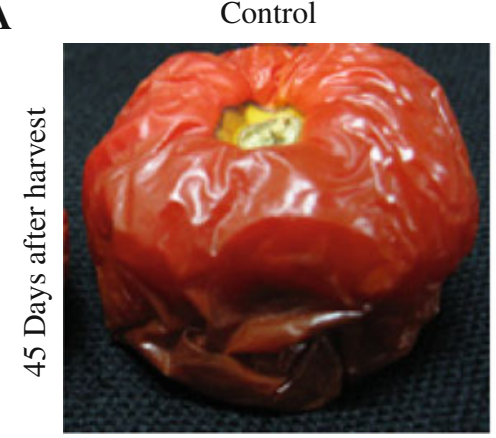

B

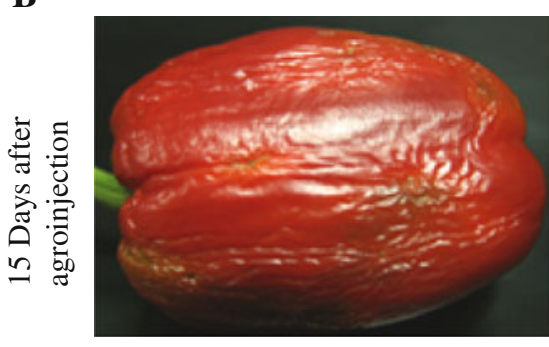

RNAi- $\alpha$-Man

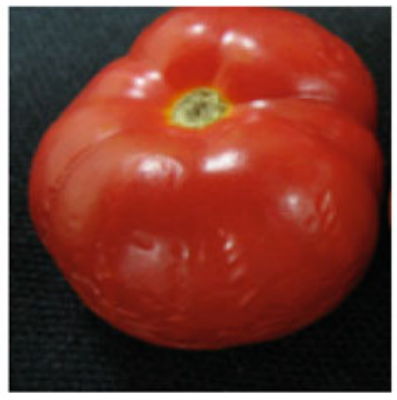

RNAi- $\alpha-$ Man

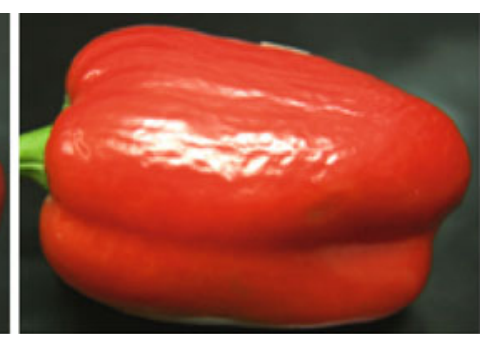

RNAi- $\beta$-Hex

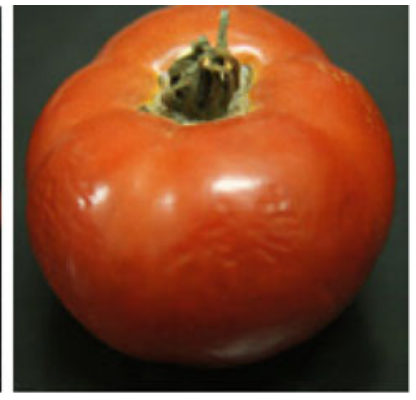

RNAi- $\beta$-Hex

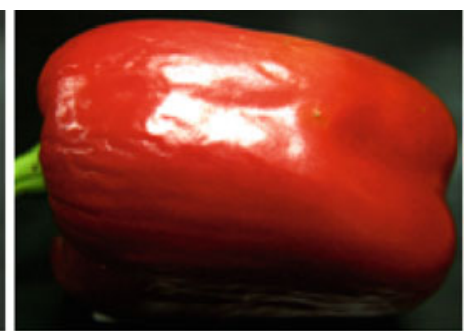

Fig. 3 Enhancement of fruit shelf life (a) tomato (climacteric fruit), and (b) capsicum (non-climacteric fruit), by silencing $\mathrm{N}$-glycan processing enzymes (alpha-mannosidase and beta-hexosaminidase);

ethylene which triggers fruit ripening in climacteric fruits. Other efforts involve reducing the rate of fruit softening by silencing the genes involved in cell wall degradation. However, these strategies have met with limited success so far as different genes need to be targeted for climacteric and non-climacteric fruits. Thus, targeting a mechanism which is common in different categories of fruits would pave the way to novel opportunities for the control of fruit softening process.

Free N-glycans that occur as the precursors of glycosylation or glycoprotein proteolysis constitute a major portion of the soluble oligosaccharide pool in the pericarp of many fruits. Free $\mathrm{N}$-glycans were found to be present in the fruit at all stages of development, and their amount predominantly increases when fruit ripen. Two $\mathrm{N}$-glycan processing enzymes $\alpha$-mannosidase ( $\alpha$-Man) and $\beta$-D- $N$-acetylhexosaminidase $(\beta$-Hex $)$ were targeted in our laboratory for the genetic manipulation through biotechnology to control fruit softening during ripening. For the first time, we cloned and patented $\alpha$-Man and $\beta$-Hex genes. Silencing of $\alpha$-Man and $\beta$-Hex genes in transgenic tomato plants through RNAi technology resulted in enhanced fruit shelf life, due to the reduced rate of fruit softening. Transgenic RNAi tomatoes (Fig. 3) were found to be ca. 2.5- and twofold firmer in the case of $\alpha$-Man and $\beta$-Hex suppressing RNAi lines, respectively. Transgenic tomatoes exhibited ca. 30 days of prolonged shelf life [14]. This genetic manipulation had no negative effect on phenotype, including yield. Moreover, RNAi-mediated suppression of $\alpha$-Man and $\beta$-Hex in the ethylene is necessary for the ripening of climacteric fruits, but not for non-climacteric fruits

non-climacteric fruits, e.g., capsicum (Fig. 3) also leads to enhancement of fruit shelf life [7]. It is evident from our research that $\mathrm{N}$-glycan processing is involved in ripening-associated fruit softening in both climacteric and non-climacteric fruits. Thus, genetic manipulation of $\mathrm{N}$-glycan processing is a novel and important strategy to prolong fruit shelf life in both climacteric and non-climacteric fruits.

\section{Conclusion}

Genetically modified crops have huge potential to solve the problem of global food and nutritional security. For the last three decades, our laboratory has been involved in genetic improvement of major crops through transgenic technology which resulted in protein-rich potato, oxalate-free, and fungal disease-resistant tomato. We have also developed transgenic tomatoes with significantly increased shelf life. All steps from isolation of four novel genes to production of transgenic and their field release have been carried out by our group. Presently, we are in the process of transferring these novel crop improvement technologies to other economically important crops.

Acknowledgments The author thanks all the students who were involved in this study. Special thanks are due to Anjana Raina, Subhra Chakraborty, and Niranjan Chakraborty for GM potato; Anuradha Mehta and Meenu Kesarwani for oxalate-free GM tomato; and Sumit Ghosh and Vijay Meli for enhanced fruit shelf life. 


\section{References}

1. Brummell DA (2006) Cell wall disassembly in ripening fruit. Funct Plant Biol 33:103-119

2. Causier B, Kieffer M, Davies B (2002) MADS-box genes reach maturity. Science 296:275-276

3. Chakraborty S, Chakraborty N, Datta A (2000) Increased nutritive value of transgenic potato by expressing a non-allergenic seed albumin gene from Amaranthus hypochondriacus. Proc Natl Acad Sci USA 97:3724-3729

4. Chakraborty S, Chakraborty N, Agrawal L, Ghosh S, Narulaa K, Shekhar S, Naik PS, Pande PC, Chakraborti SK, Datta A (2010) Next generation protein rich potato by expressing a seed protein gene AmA1 as a result of proteome rebalancing in transgenic tuber. Proc Natl Acad Sci USA 107:17533-17538

5. Decastro MDL (1988) Determination of oxalic acid in urine. A review. J Pharm Biomed Anal 6:1-13

6. Falco SC, Guida T, Locke M, Mauvais J, Sanders C, Ward RT, Webber P (1995) Transgenic canola and soybean seeds with increased lysine. Biotechnology 13:577-582

7. Ghosh S, Meli VS, Kumar A, Thakur A, Chakraborty N, Chakraborty S, Datta A (2011) The N-glycan processing enzymes $\alpha$-mannosidase and $\beta$-D-1- $N$-acetylhexosaminidase are involved in ripening-associated softening in the non-climacteric fruits of capsicum. J Exp Bot 62:571-582

8. Hodgkinson A (1970) Determination of oxalic acid in biological material. Clin Chem 16:547-557

9. Jaynes JM, Yang MS, Espinoza N, Dodds JH (1986) Plant protein improvement by genetic engineering: use of synthetic genes. Trends Biotechnol 4:314-320

10. Kesarwani M, Azam M, Natarajan K, Mehta A, Datta A (2000) Oxalate decarboxylase from Collybia velutips: molecular cloning and its over expression to confer resistance to fungal infection in transgenic tobacco and tomato. J Biol Chem 275:7230-7238

11. Malathi K, Padmanabhan G, Sharma PS (1970) Biosynthesis of $\beta$ - $N$-oxalyl-L- $\alpha, \beta$-diaminopropionic acid the Lathyrus sativus neurotoxin. Phytochemistry 9:1603-1610

12. Matthews BF, Hughes CA (1993) Nutritional improvement of the family of amino acids in edible crop plants. Amino Acids 4:21-34

13. Mehta A, Datta A (1991) Oxalate decarboxylase from Collybia Velutipes: purification, characterization cDNA cloning. J Biol Chem 266:23548-23553

14. Meli VS, Ghosh S, Prabha TN, Chakraborty N, Chakraborty S, Datta A (2010) Enhancement of fruit shelf life by suppressing $\mathrm{N}$-glycan processing enzymes. Proc Natl Acad Sci USA 107: 2413-2418

15. Mickelsen O, Yang MG, Goodhart RS (1973) Progress in neuropathology. In: Goodhart RS, Shils ME (eds) Modern nutrition in health and disease: dietotherapy, 5th edn. Lea and Febiger, Philadelphia, pp 412-433

16. Raina A, Datta A (1992) Molecular cloning of a gene encoding a seed specific protein with nutritionally balanced amino acid composition from Amaranthus. Proc Natl Acad Sci USA 89: 11774-11778

17. Spencer PS, Ludolph A, Dwivedi MP, Roy DN, Hugon DN, Schaumburg HH (1986) Lathyrism: evidence for role of the neuroexcitatory amino acid BOAA. Lancet 11:1066-1067

18. Vicente AR, Saladie M, Rose JKC, Labavitch JM (2007) The linkage between cell wall metabolism and fruit softening: looking to the future. J Sci Food Agric 87:1435-1448 